\title{
Effect of Data Assimilation Using WRF-3DVAR for Heavy Rain Prediction on the Northeastern Edge of the Tibetan Plateau
}

\author{
Junhua Yang, ${ }_{1}^{1}$ Keqin Duan, ${ }^{1,2}$ Jinkui Wu, ${ }^{1}$ Xiang Qin, ${ }^{1}$ Peihong Shi, \\ Huancai Liu, ${ }^{1}$ Xiaolong Xie, ${ }^{3}$ Xiao Zhang, ${ }^{1}$ and Jianyong Sun ${ }^{1}$ \\ ${ }^{1}$ State Key Laboratory of Cryospheric Sciences, Cold and Arid Regions Environmental and Engineering Research Institute, \\ Chinese Academy of Sciences, Lanzhou 730000, China \\ ${ }^{2}$ Tourism and Environmental College, Shanxi Normal University, Xian 710000, China \\ ${ }^{3}$ Resource and Environment College of Lanzhou University, Lanzhou, Gansu 730000, China
}

Correspondence should be addressed to Keqin Duan; kqduan@lzb.ac.cn

Received 25 June 2014; Revised 17 September 2014; Accepted 22 September 2014

Academic Editor: Eduardo García-Ortega

Copyright (C) 2015 Junhua Yang et al. This is an open access article distributed under the Creative Commons Attribution License, which permits unrestricted use, distribution, and reproduction in any medium, provided the original work is properly cited.

\begin{abstract}
The numerical weather prediction (NWP) is gaining more attention in providing high-resolution rainfall forecasts in the arid and semiarid region. However, the modeling accuracy is negatively affected by errors in the initial conditions. Here we investigate the potential of data assimilation in improving the NWP rainfall forecasts in the northeastern Tibetan Plateau. Three of threedimensional variational (3DVar) data assimilation experiments were designed on running the advanced research weather research forecast (WRF) model. Two heavy rain events selected with different rainfall distribution in space and time are utilized to examine the improvement for rainfall forecast after data assimilation. For the spatial distribution, the improvement of rainfall accumulation and area is obvious for the both two events. But for the temporal variation, the improvement is more obvious for the event with even rainfall distribution in time, while the effect of data assimilation is not ideal for the rainfall event with uneven distribution in space and time. It is noteworthy that, for both the spatial and temporal distribution of rainfall, satellite radiances have greater effect on rainfall forecasts than surface and upper-air meteorological observations in this high-altitude region. Moreover, the data assimilation experiments provide more detail information to the initial fields.
\end{abstract}

\section{Introduction}

Precipitation is a crucial component in the hydrological cycle of the Earth and has a profound influence on climate and hydrology at regional to global scales [1]. A high-resolution heavy rainfall forecast plays an important role in accurate flood forecasting and water resource regulation [2], especially in the arid and semiarid region of northwest China where precipitation is crucial for water resources, and the heavy rain often results in flash flood in summer. Therefore, providing accurate rainfall forecasts over northwest China using the numerical weather prediction (NWP) is of prime importance. Weather research and forecast (WRF) is the latest generation mesoscale NWP model. Recent studies have shown that the WRF model has good potential in capturing rainfall features such as rainfall timing, location, and evolution [3-5].
However, for producing accurate values for rainfall quantities, the results are not ideal due to the low-quality initial conditions [6], which can be improved by data assimilation [7].

With the improvement of the NWP models, several data assimilation skills, such as three and four-dimensional variational methods (3DVar/4DVar), ensemble Kalman filers (EnKF), and latent heat nudging (LHN) have been developed in the methods of variational and ensemble $[8,9]$. Although the 4D-Var and EnKF methods show great potential, they still suffer from unaffordable computer costs for operational NWPs. In continuous cycling mode, 3DVar performs better in producing rational analyses of hydrometeorological fields with greater computational efficiency than 4DVar, EnKF, and LHN $[10,11]$.

Real-time observations have generally been used in the assimilation systems and shown to improve markedly 


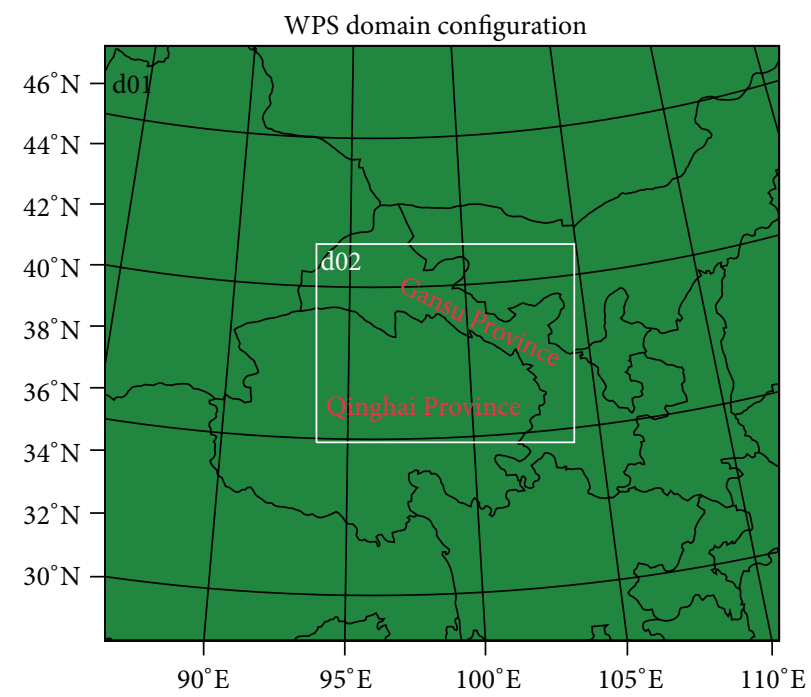

FIGURE 1: Domains for the ARW-WRF forecasts. The outer box is the coarse grid with a resolution of $12 \mathrm{~km}$ (d01); the inner box is the nested grid (d02) with a resolution of $4 \mathrm{~km}$.

the performance of NWP models, in spite of the poor initial conditions provided by the global NWP models [12]. In the case of high temporal and spatial resolution satellite data, the European Center for Medium-Range Weather Forecasts (ECMWF) pioneered the direct assimilation of microwave radiance data affected by precipitation, first in a $1+4$ Dvar assimilation approach $[13,14]$ and later in an implementation of all-sky radiance assimilation in the operational 4Dvar system $[15,16]$. Additionally, many investigations have shown that rainfall forecasts from the NWP models can be improved noticeably with the assimilation of radar reflectivity [17-19] or radar-derived precipitation data $[20,21]$. Nevertheless, the remote sensing data need to be validated against ground truth [22], and surface observations have a wealth of information that can be used to simulate mesoscale weather phenomena [23]. Therefore, the assimilation of surface observations in a NWP model is likely to improve the model performance as well. Previous studies have been made to improve simulations of weather parameters by using direct or modeled surface observations. These include the assimilation of temperature, water vapor, mixing ratio and winds [24], and $2 \mathrm{~m}$ potential temperature, $2 \mathrm{~m}$ dew point temperature, and $10 \mathrm{~m}$ wind observations [25] into the NWP model, to determine planetary boundary layer (PBL) profiles and to analyse the surface cold pool, respectively. The results show a marked improvement in the model simulations after the assimilation. In the WRF assimilation system, previous research has also shown that, by assimilating only the satellite data, the improvement in precipitation forecasts is not as great as when the assimilation of satellite data is combined with that of surface observations $[26,27]$.

In this study, the WRF-3Dvar system is used to explore the effect of the assimilation of NCAR surface and upperair observations and of AMSU-A and AMSU-B microwave radiance data on forecasts of heavy precipitation on the northeastern Tibetan Plateau. Two heavy rain events that occurred in June, 2013, were selected in order to evaluate the improvement for rainfall forecast after data assimilation. The paper is organized as follows. Section 2 gives a concise overview of the method and experiment design. Section 3 provides information on the study area and the data. The results of the data assimilation experiments are presented and evaluated in Section 4, and conclusions are given in Section 5.

\section{Method and Experimental Design}

2.1. WRF Model Set-Up. The numerical data assimilation experiments in this study are conducted using the Advanced Research WRF model Version 3.5. WRF is a nonhydrostatic, primitive-equation, mesoscale meteorological model with advanced dynamics, physics, and numerical schemes (details of the model is at http://www.mmm.ucar.edu/). As shown in Figure 1, the model domains are two-way nested with $12 \mathrm{~km}$ $(208 \times 182)$ and $4 \mathrm{~km}(235 \times 182)$ horizontal spacing. Each domain has 28 vertical pressure levels with the top level set at $50 \mathrm{hPa}$. The WRF physical parameterization schemes used in this study include the Purdue Lin microphysical parameterization, Rapid Radiative Transfer Model (RRTM) longwave radiation, Dudhia shortwave radiation, MoninObukhov surface layer, Noah land surface, Mellor-YamadaJanjic (MYJ) planetary boundary layer scheme, and GrellDevenyi (GD) cumulus scheme. The projection method is Lambert.

2.2. 3D-Var Data Assimilation. Data assimilation is the technique by which observations are combined with a NWP product (called the first guess or background field) and their respective error statistics to provide an improved estimate (the analysis) of the atmospheric (or oceanic) state. Variational (Var) data assimilation achieves this through 
the iterative minimization of a prescribed cost (or penalty) function [28]:

$$
\begin{aligned}
J(x)= & \frac{1}{2}\left(x-x^{b}\right)^{T} B^{-1}\left(x-x^{b}\right) \\
& +\frac{1}{2}\left(y-y^{0}\right)^{T} R^{-1}\left(y-y^{0}\right),
\end{aligned}
$$

where $x$ is the analysis to be found that minimizes the cost function $J(x), x^{b}$ is the first guess of the NWP model, $y^{0}$ is the assimilated observation, and $y=H(x)$ is the model-derived observation transformed from the analysis $x$ by the observation operator $H$ for comparison against $y^{0}$. The solution for the cost function given by (1) represents a posteriori maximum likelihood (minimum variance) estimate of the true state given the two sources of a priori data: the first guess $x^{b}$ and the observation $y^{0}$ [29]. The fit to individual observation points is weighted by the estimates of their errors, that is, $B$ and $R$, which are the background error covariance matrix and the observation error covariance matrix, respectively.

The WRF-3DVar system developed by Barker et al. [10] is used in this study in tandem with the WRF model for assimilating the satellite radiance data and the traditional observations. The performance of the data-assimilation system largely depends on the plausibility of the background error covariance (BE), that is, the matrix $B$ in (1). In this study, the "CV5" background error option is used with the control variables of stream function, unbalanced temperature, unbalanced potential velocity, unbalanced surface pressure, and pseudo relative humidity. The background error covariance matrix is generated via the National Meteorological Center (NMC) method [30] for our own forecasting domain.

2.3. Experimental Design. Four sets of experiments have been conducted using two domains. As shown in Table 1 , the model simulation without data assimilation will be referred to as the control experiment (CTRL). Three assimilation experiments are designed using different observation parameters from different data sources. In the DA-OBS experiment, measurements of pressure, geopotential height, temperature, dewpoint temperature, wind direction, and speed from NCAR are assimilated, while in the DA-SAT experiment, only satellite radiance data are assimilated. Finally, in the DABOTH experiment, both NCAR observations and AMSU-A (B) radiance data are assimilated.

\section{Study Area and Data}

As shown in Figure 2, the northeastern of the Tibetan Plateau $\left(94^{\circ} 39^{\prime}-103^{\circ} 27^{\prime} \mathrm{E}, 35^{\circ} 51^{\prime}-40^{\circ} 31^{\prime} \mathrm{N}\right)$ range of elevation between $758 \mathrm{~m}$ and $5725 \mathrm{~m}$ a.s.l is the head of many inland rivers, which play an important role in the hydrology and agriculture in the downstream arid region. A total of 43 national observation stations have been used to verify the spatial distribution of the simulated precipitation, among which the Wulan station has the highest elevation of $3800 \mathrm{~m}$ and Dunhuang has the lowest altitude of $1137 \mathrm{~m}$. The observed
TABLE 1: Details of the observed data used in the assimilation experiments.

\begin{tabular}{ll}
\hline Experiment name & Assimilated data \\
\hline CTRL & $\begin{array}{l}\text { No data assimilation } \\
\text { NCAR surface and upper-air } \\
\text { observation }\end{array}$ \\
DA-OBS & $\begin{array}{l}\text { AMSU-A and AMSU-B radiance } \\
\text { data }\end{array}$ \\
DA-SAT & NCAR observation and \\
& AMSU-A (B) radiance data \\
\hline
\end{tabular}

precipitation at Laohugou station (elevation $4200 \mathrm{~m}$ ) has been used to evaluate the temporal variations of the simulated rainfall, which is measured by T200B every half hour.

The initial and boundary conditions necessary to run the WRF are the ERA-Interim data at $1^{\circ} \times 1^{\circ}$ grid resolution obtained from the European Centre for Medium-Range Weather Forecasts (ECMWF), rather than the NCEP-NCAR Final Analysis (FNL) data. This is because several studies have demonstrated that the reliability of ERA-Reanalysis data is higher than the NCEP data in China $[31,32]$. In the model integration, the coordinates of the central point are $38.1^{\circ} \mathrm{N}$ and $98.9^{\circ} \mathrm{E}$. WRF-3DVar experiments have been conducted with modified initial conditions which were obtained by assimilating other measured data. The assimilated data includes NCAR surface and upper-air observations and AMSUA and AMSUB radiance data. The surface and upperair data assimilated in this study are obtained from the "ds337.0" in the NCAR archives, which contain measurements of pressure, geopotential height, temperature, dew point temperature, wind direction, and speed from fixed and mobile land/sea stations. The data are initially downloaded in PREPBUFR format and can be assimilated directly into WRFDA. The AMSU-A and AMSU-B satellite radiance data (NOAA-15/16/17/18/19) from the NOAA ATOVS instruments can be read in WRFDA via CRTM2.0.2, which is in BUFR format.

\section{Results and Discussion}

\subsection{Impacts of Data Assimilation on the Precipitation Forecast}

4.1.1. Rainfall Event. In June 2013, two heavy rain events occurred in the northeast of the Tibetan Plateau. The durations of the events and the maximum/mean rainfall accumulation observed by rain gauge network are shown in Table 2. The two events are of different types according to the evenness of rainfall distribution in time and space. Figure 3 illustrates the spatial distribution of the rainfall accumulation for the durations of the two events, while Figure 4 presents the time series bars and the cumulative curves of the observed precipitation for the two events at Laohugou station. By comparing the evenness of the rainfall distribution in time and space in Figures 3 and 4, it can be found that Event $A$ has even rainfall distribution neither in space nor in time. The rainfall distribution of Event B is also uneven in space, but continuous and almost constant in time. 
TABLE 2: Durations, maximum/mean rainfall accumulation, and spatial/temporal evenness of the heavy rain events.

\begin{tabular}{lcccccc}
\hline Event ID & Start time & End time & Spatial evenness & Temporal evenness & Maximum precipitation & Mean precipitation \\
\hline A & $18 / 6 / 20130: 00$ & $19 / 6 / 201324: 00$ & 1.46 & 1.44 & 42.5 & 6.7 \\
B & $7 / 6 / 20130: 00$ & $7 / 6 / 201324: 00$ & 1.15 & 0.63 & 23.5 & 5.3 \\
\hline
\end{tabular}

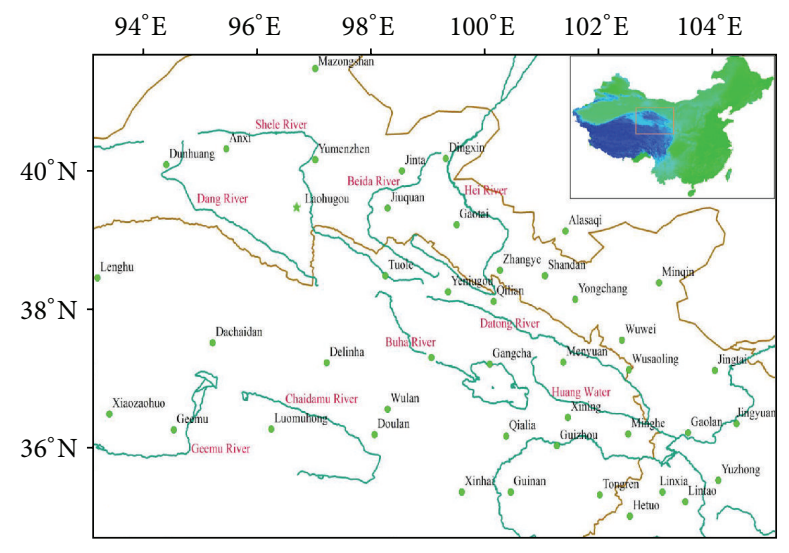

- Rain-gauge stations
- Laohugou
River

FIGURE 2: Location map showing the northeastern edge of the Tibetan Plateau and 44 observation stations.

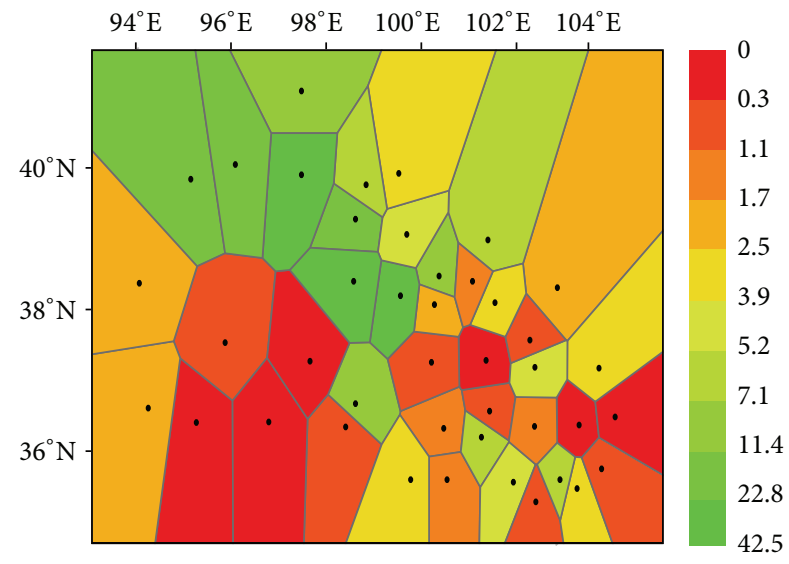

(a)

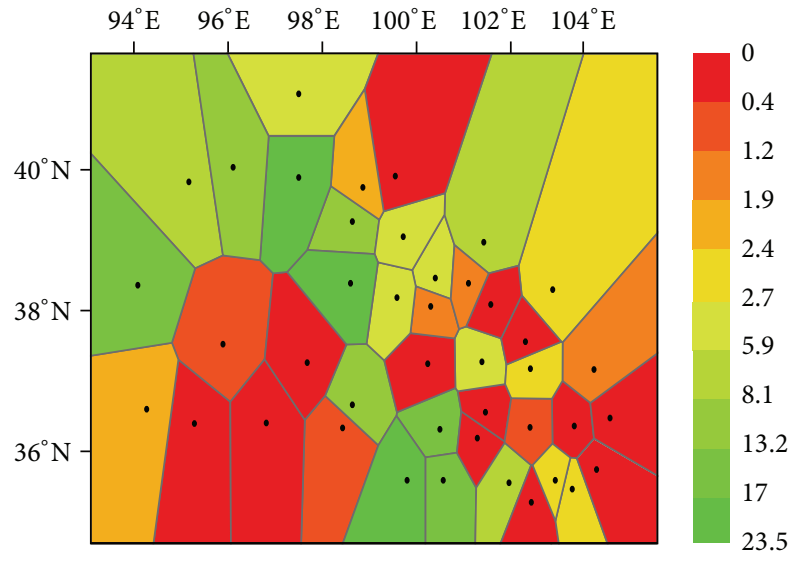

(b)

Figure 3: Spatial distribution of the rainfall accumulation for the durations of the two events shown in Thiessen polygons: (a) Event A; (b) Event B.

As for the meteorological characteristics of the storm events according to the weather analysis charts, Event A is likely caused by very strong local convections, and Event B may be a stratiform storm.

The rainfall evenness/unevenness of the two heavy rain events can be further verified quantitatively by using the coefficient of variability $(\mathrm{CV})$ :

$$
\mathrm{CV}=\sqrt{\frac{1}{N} \sum_{i=1}^{N}\left(\frac{x_{i}}{\bar{x}}-1\right)^{2}}
$$

where $x_{i}$ is the rainfall accumulation of each rain gauge $i$ (when calculating the evenness in space) or the average areal rainfall at each time step $i$ (for the evenness in time), $\bar{x}$ is the mean value of $x_{i}$, and $N$ is the total number of rain gauges or the total number of the time steps. The results of the two rainfall events are also shown in Table 2. A larger CV value represents higher variability thus less even rainfall distribution. The CV value of the spatial evenness for Event A is larger than that for Event B, which means Event A has higher variability in space.

4.1.2. Spatial Distribution of Precipitation. In Figure 5, compared with CTRL experiment (Figure 5(a)), the forecasts of precipitation area and accumulation are increased noticeably depending on different data assimilation. The CTRL 


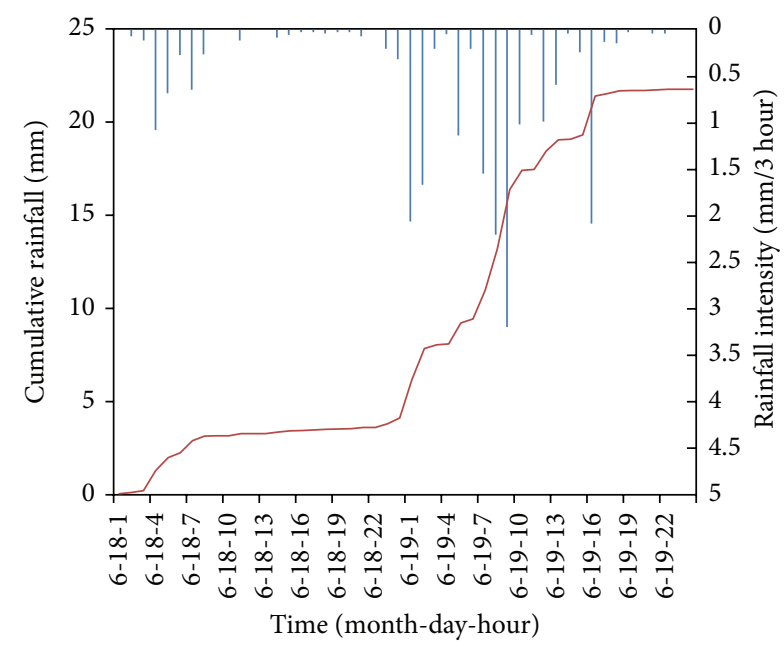

(a)

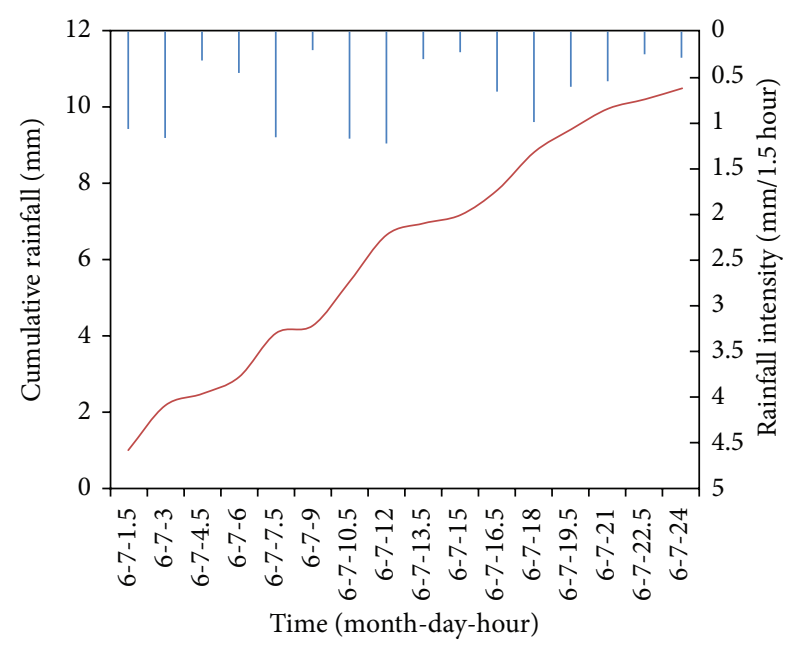

(b)

FIGURE 4: The time series bars and the cumulative curves of the observed precipitation for the two heavy rainfall events at Laohugou station: (a) Event A; (b) Event B.

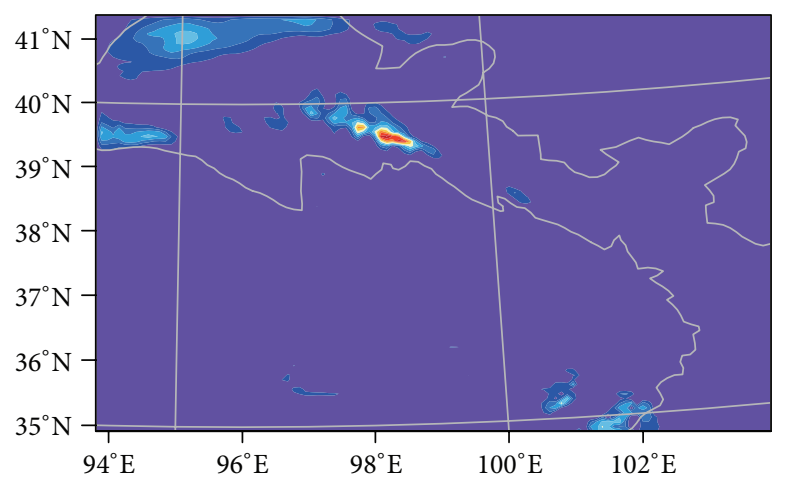

(a)

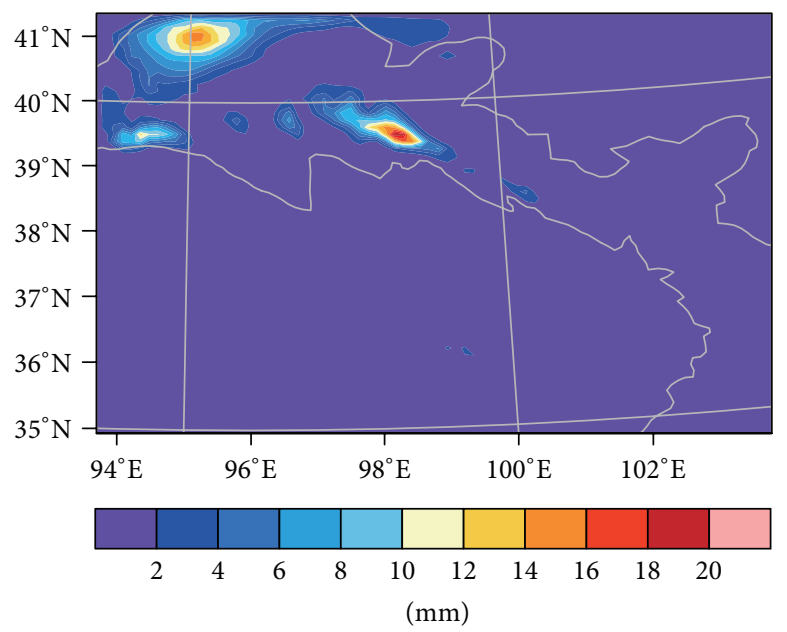

(c)

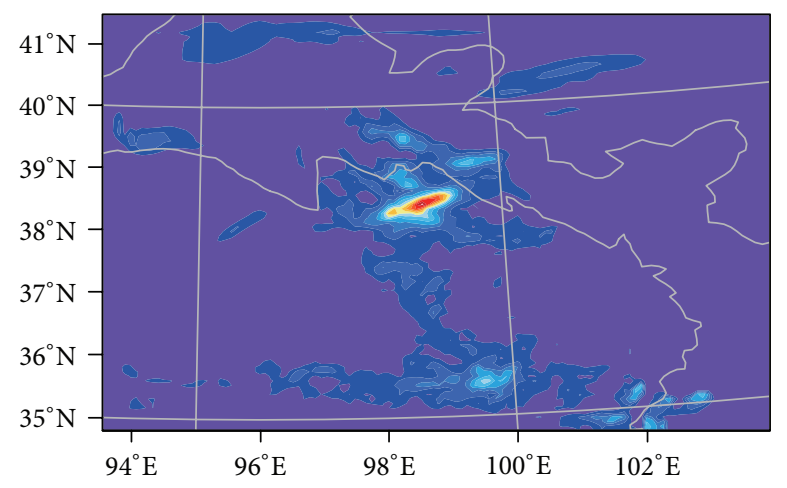

(b)

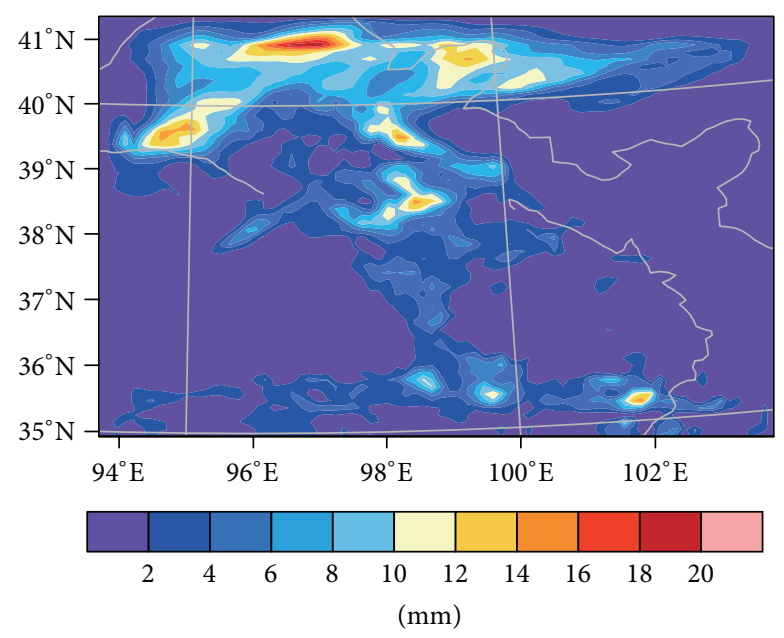

(d)

FIGURE 5: The forecast precipitation for Event A from the different numerical experiments: (a) CTRL; (b) DA-SAT; (c) DA-OBS; (d) DABOTH. 


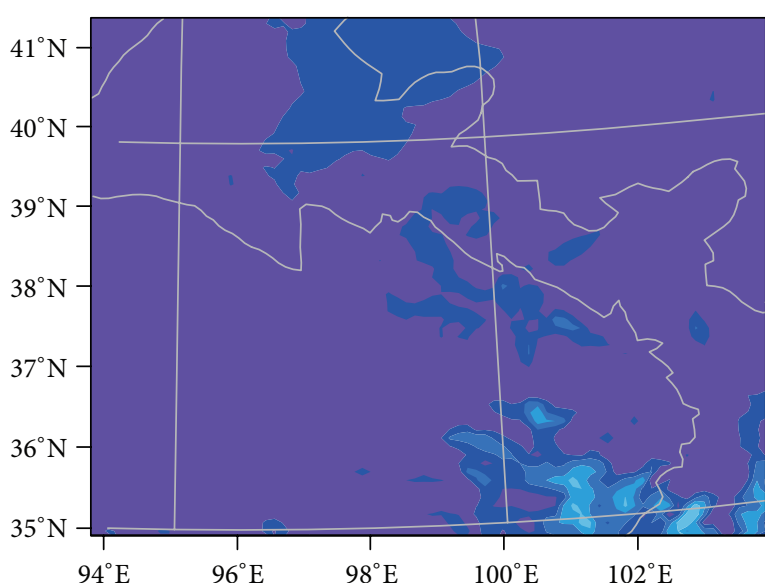

(a)

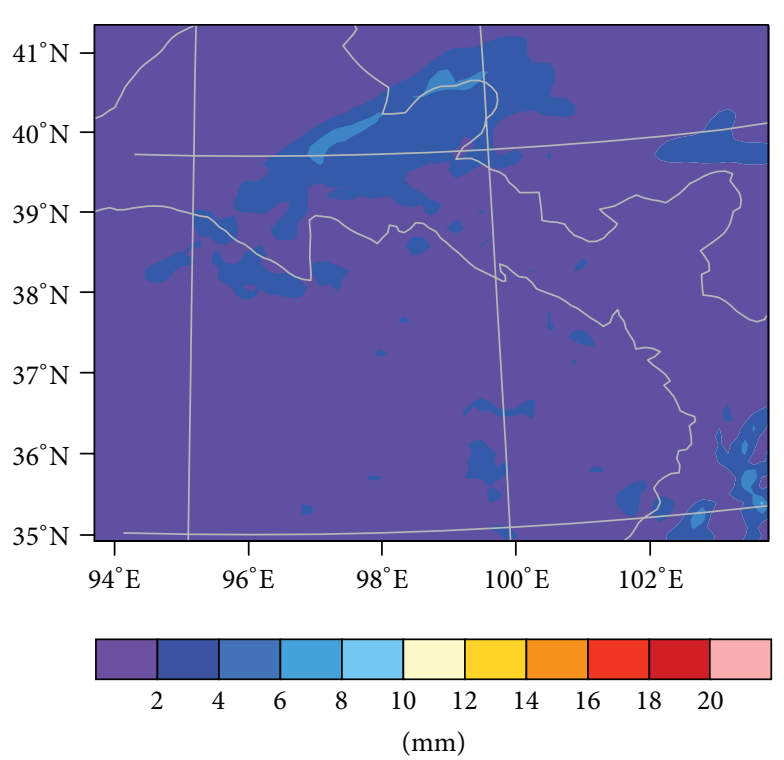

(c)

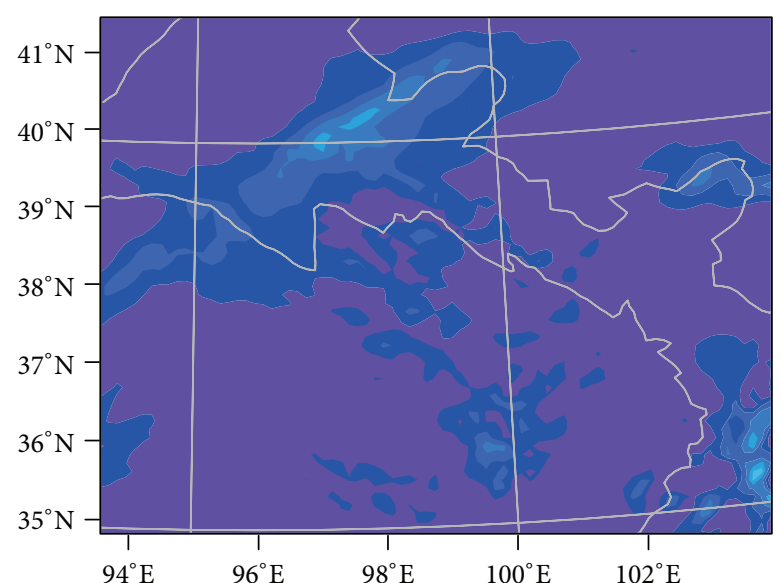

(b)
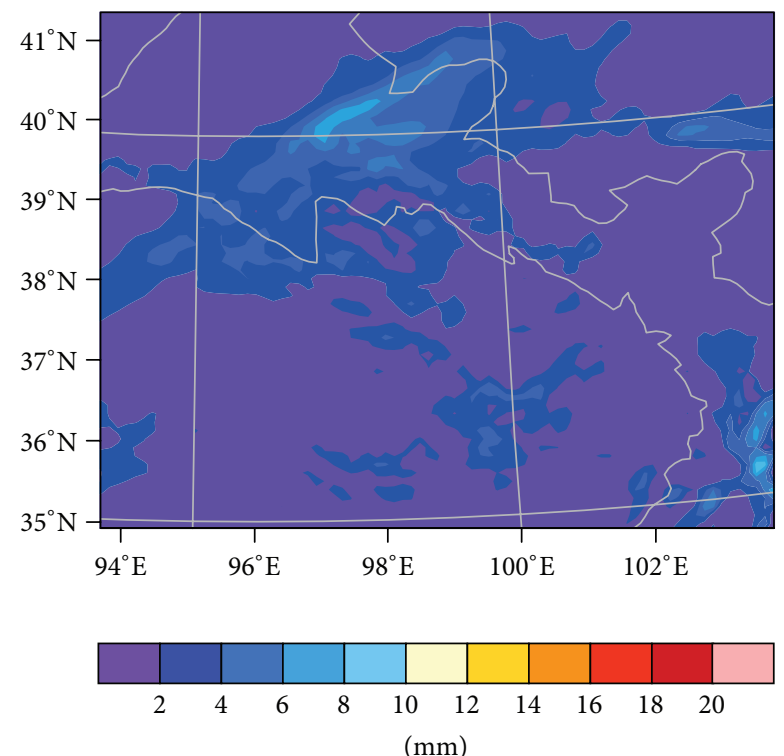

(d)

FiguRE 6: The forecast precipitation for Event B from the different numerical experiments: (a) CTRL; (b) DA-SAT; (c) DA-OBS; (d) DABOTH.

experiment predicts only a small amount of rainfall on the northwestern of the study area, while in DA-SAT experiment precipitation area extends to the central and southern regions of the study area and rainfall accumulation increases significantly (Figure 5(b)). But in the northwest of the region, the rainfall accumulation for DA-SAT experiment is similar with that shown in Figure 5(a). In DA-OBS experiment (Figure 5(c)), precipitation accumulation on the northwestern of the region is greater than that in CTRL experiment, but the precipitation area is similar in both experiments. Figure 5(d) shows the result of DA-BOTH experiment, in which the precipitation area is the largest and accumulation is the biggest compared with the other three experiments.

The results for Event B are shown in Figure 6. The precipitation area on the northwestern of the study region is significantly increased by DA-SAT experiment (Figure 6(b)) relative to that in CTRL experiment. In Figure 6(c), the precipitation area in DA-OBS experiment is same as that in Figure 6(a), but the precipitation accumulation is obviously decreased on the southeastern of the region. Figure 6(d) shows the DA-BOTH experiment result, which has the similar precipitation area and accumulation as shown in DA-SAT experiment.

To sum up, the data assimilation has important influence on the precipitation forecast with significantly changes of the rainfall area and accumulation. It should be noticed that the effects of the forecast depends on the different rainfall event.

The rain-gauge data were used to analyze the changed precipitation area and accumulation after data assimilation experiments. Figure 7 compares the measured and modeled results in the rainfall Event A. In CTRL experiment (Figure 7(a)), almost all the triangles lie below the line $y=x$. However, in DA-SAT experiment, the green triangles which represent the observation sites (Qilian, Yeniugou, Tuole, 


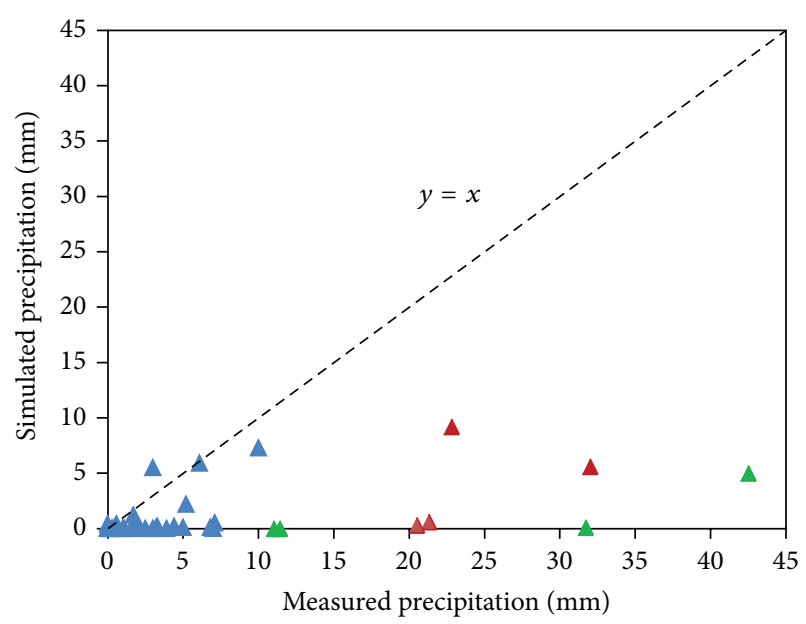

(a)

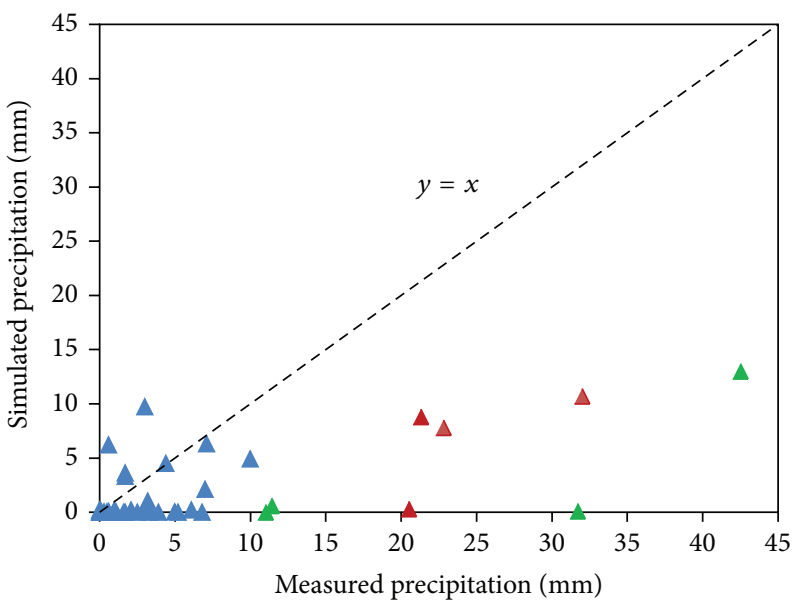

(c)

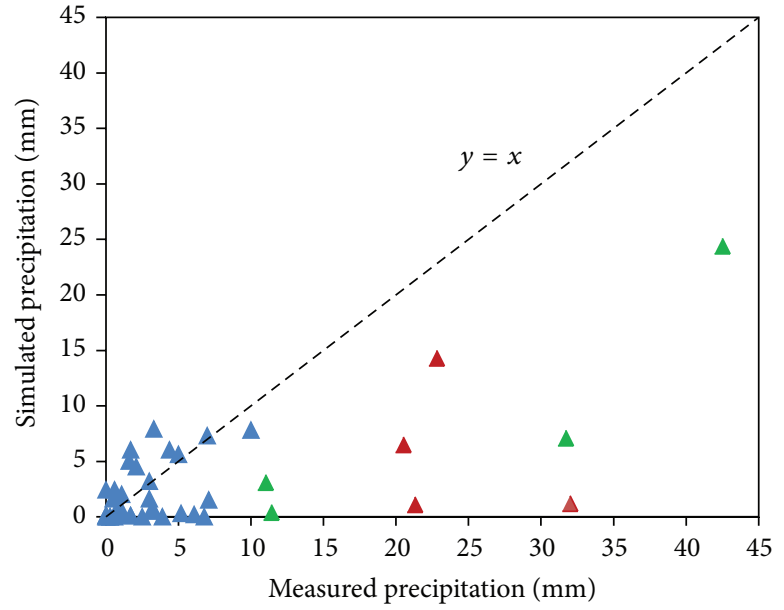

(b)

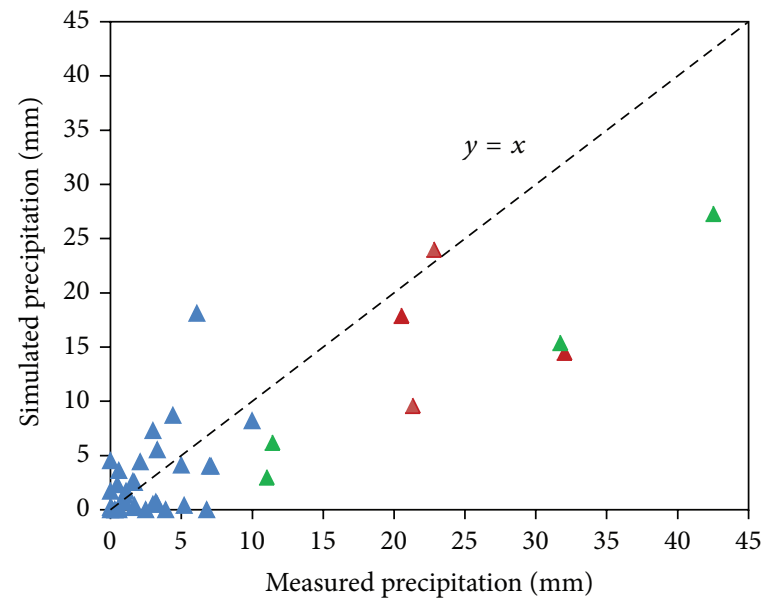

(d)

Figure 7: Differences between rainfall values measured at the sites and those from the numerical experiments for Event A: (a) CTRL; (b) DA-SAT; (c) DA-OBS; (d) DA-BOTH.

and Wulan) in the central and southern regions of the study area are closer to the line $y=x$ (Figure 7(b)). That is to say, DA-SAT experiment improves the predicted accuracy for the central and southern regions of the study area, through providing greater precipitation accumulation. Similarly, in Figure 7(c) for DA-OBS experiment, the red triangles which represent the observation sites (Jiuquan, Yumenzheng, Anxi, and Dunhuang) in northwestern of the region are closer to the line $y=x$ than that is shown in CTRL experiment. In DABOTH experiment, all the red and green triangles are closest to the line $y=x$ (Figure $7(\mathrm{~d})$ ).

It is noticed that, in Figure 8, many more triangles for Event $\mathrm{B}$ lie above the $y=x$ line than Event A. As shown in CTRL experiment (Figure 8(a)), the green triangles which represent observation sites (Hezuo, Lintao, linxia, and Yuzhong) on the southeastern of the study area are lie above and far away from the $y=x$ line. After data assimilation, the green triangles in three data assimilation experiments are closer to the $y=x$ line in Figures $8(\mathrm{~b})-8(\mathrm{~d})$. The red triangles represent the observation sites (Jiuquan, Tuole,
Dingxin, and Jinta) in the northwestern of the study area. In DA-SAT experiment (Figure 8(b)), two red triangles with more than $10 \mathrm{~mm}$ of rainfall are closer to the $y=x$ line, while in DA-OBS experiment (Figure 8(c)), other two red triangles with less than $5 \mathrm{~mm}$ of rainfall are closer to the $y=x$ line, compared with that in Figure 8(a). In DA-BOTH experiment (Figure $8(\mathrm{~d})$ ), the results are similar to that as shown in DASAT experiment, except the red triangles are closer to the $y=x$ line.

The above results suggest that data assimilation have positive effects on the rainfall forecast, through changing the rainfall area and accumulation for the study area. And for the two events with different evenness in time and space, the results after data assimilation are different. For Event A, data assimilation experiments provide larger rainfall areas and accumulation to improve the predicted accuracy. And for Event B, data assimilation experiments improve the accuracy on the southeastern of the study area by providing smaller precipitation accumulation. This means that CTRL experiment underestimates the convective rainfall for Event 


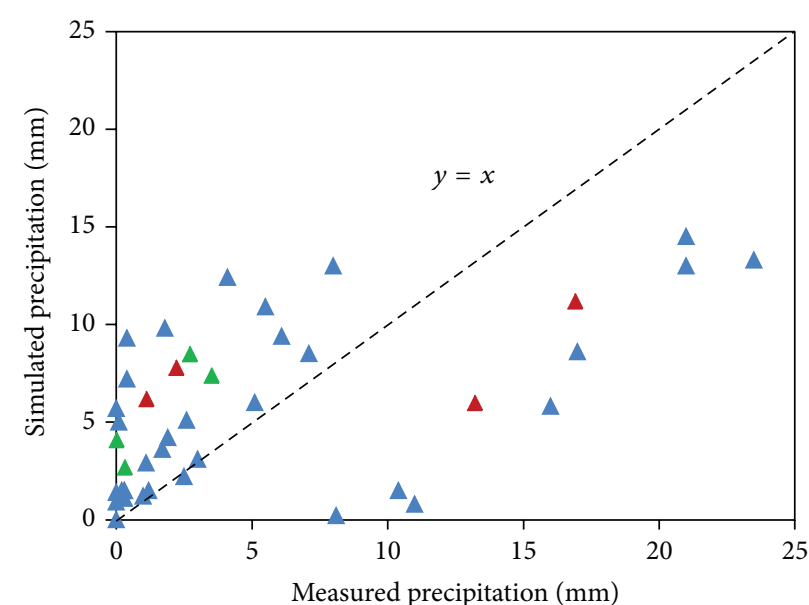

(a)

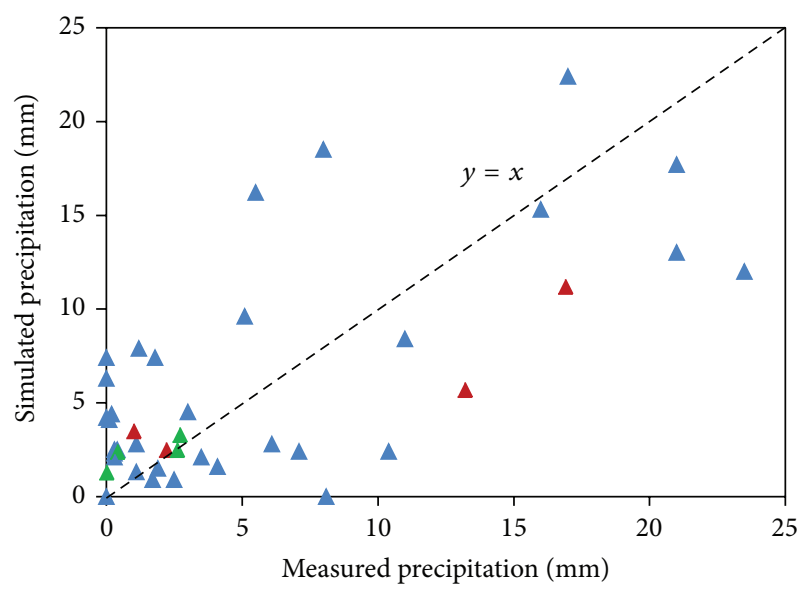

(c)

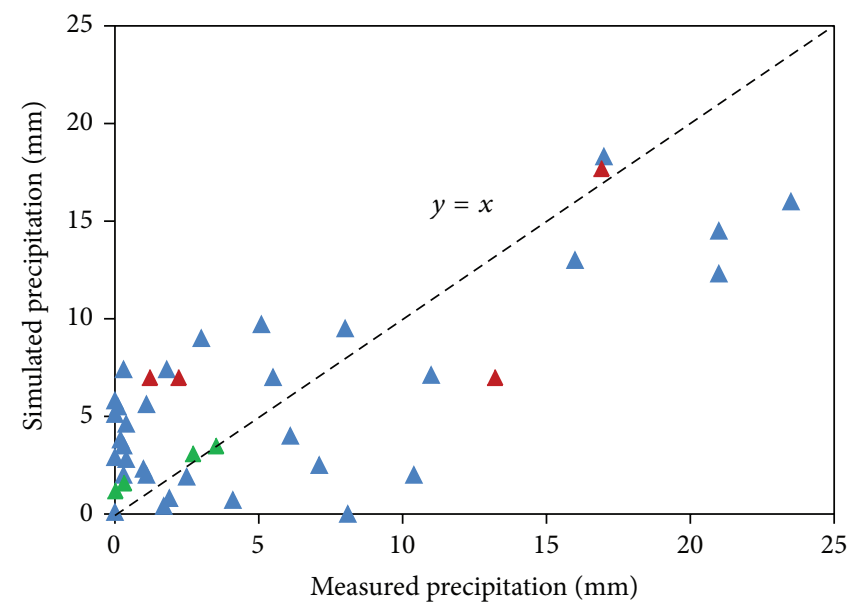

(b)

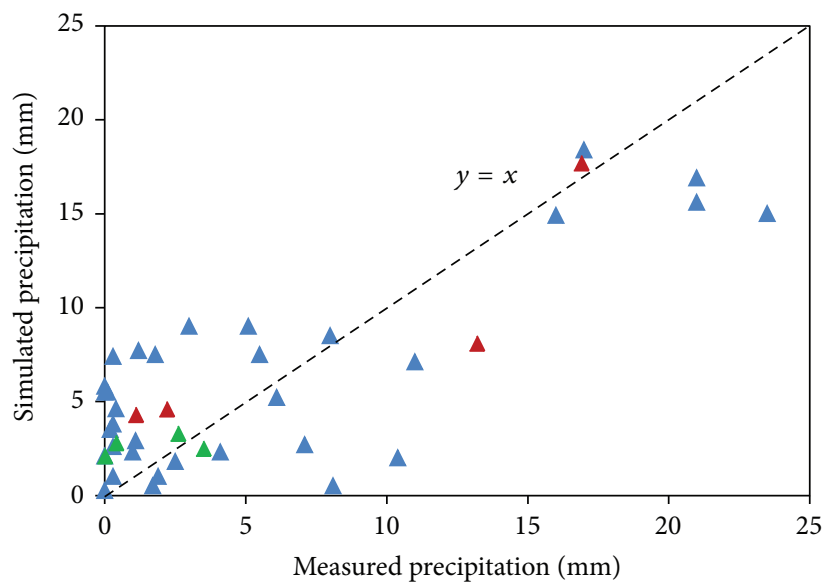

(d)

FIGURE 8: Differences between rainfall values measured at the sites and those from the numerical experiments for Event B: (a) CTRL; (b) DA-SAT; (c) DA-OBS; (d) DA-BOTH.

A and overestimates the stratiform rainfall of Event B on the southeastern of the region.

In order to evaluate quantitatively the impact of data assimilation experiments which have positive effects on the rainfall forecast, rain-gauge data from 43 sites were used. Table 3 shows the comparison between the measured and modeled results. The CTRL experiments have the lowest precision of simulation for both Event A and Event B, whose $R^{2}$ are the smallest and RMSE are the biggest compared with three data assimilation experiments. The greatest improvement appears in DA-BOTH experiment for the two events. For Event A, the $R^{2}$ for DA-BOTH experiment is increased by 0.46 and its RMSE is reduced by 4.7 , and for Event B, the $R^{2}$ for DA-BOTH experiment is increased by 0.32 and its RMSE is reduced by 0.6 . Additionally, it is found that in DA-SAT experiment the improvement is bigger than DAOBS experiment. The ME of rainfall accumulation shows that for the entire rainfall range it has positives value for Event A but has negative value for Event $\mathrm{B}$. This means that the four experiments produce underestimated rainfall accumulations for Event A, but overestimated rainfall accumulations for
Event B. That is because in the precipitation ranges of $0-5 \mathrm{~mm}$ and $5-10 \mathrm{~mm}$, almost all the ME values are positive for Event $\mathrm{A}$ and all the ME are negative for Event $\mathrm{B}$.

In this section for the two events, it is found that the forecast precision in DA-SAT experiment is higher than that in DA-OBS experiment. This may be because there are few stations located on the high-altitude region of northeastern Tibetan Plateau. DA-BOTH experiment has the biggest precision compared with the other two data assimilation experiments, which means that the improvement after the assimilation of the satellite radiances combined with surface and upper-air meteorological observations is greater than that after only assimilating satellite radiances.

4.1.3. Temporal Variations of Precipitation. The greater difference between Event A and Event B is the rainfall distribution in time. Figure 9(a) shows the rainfall intensities and cumulative curves of the measured and modeled results for Event $\mathrm{A}$ at Laohugou station. The cumulative curves of CTRL experiment are lie below and far away from that of the measured values. However, during the period from 
TABLE 3: Differences between observation and numerical experiments.

\begin{tabular}{|c|c|c|c|c|c|c|c|}
\hline Event ID & Experiments & $R^{2}$ & RMSE & $0-5 \mathrm{~mm}$ & $\begin{array}{c}\mathrm{ME} \\
\text { 5-10 mm }\end{array}$ & $10-42.5(23.5)$ & $0-42.5(23.5)$ \\
\hline \multirow{4}{*}{ Event A } & CTRL & 0.24 & 10.5 & -0.15 & 4.2 & 21.6 & 5.6 \\
\hline & DA-SAT & 0.43 & 8.1 & 1.2 & 3.1 & 17.2 & 3.5 \\
\hline & DA-OBS & 0.33 & 9.2 & 0.4 & 3.9 & 18.9 & 4.6 \\
\hline & DA-BOTH & 0.70 & 5.8 & -0.3 & 1.1 & 9.5 & 1.8 \\
\hline \multirow{4}{*}{ Event B } & CTRL & 0.32 & 5.5 & -2.8 & -1.4 & 8.4 & -0.2 \\
\hline & DA-SAT & 0.59 & 5.0 & -2.4 & -1.6 & 5.4 & -0.5 \\
\hline & DA-OBS & 0.48 & 5.4 & -1.9 & -2.3 & 4.6 & -0.7 \\
\hline & DA-BOTH & 0.64 & 4.9 & -2.5 & -1.3 & 5.0 & -0.6 \\
\hline
\end{tabular}

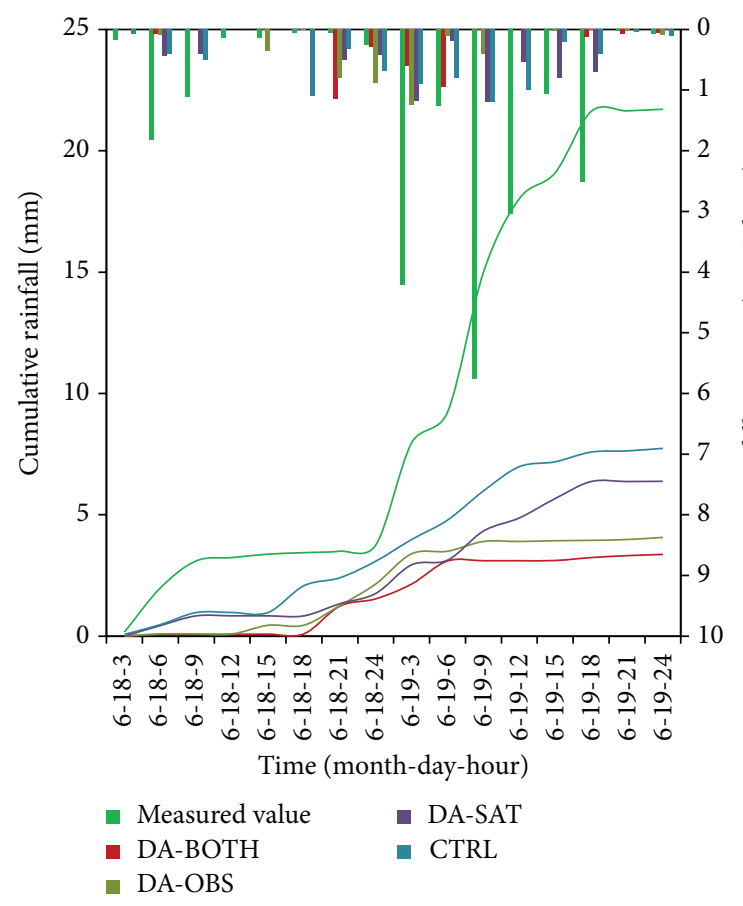

(a)

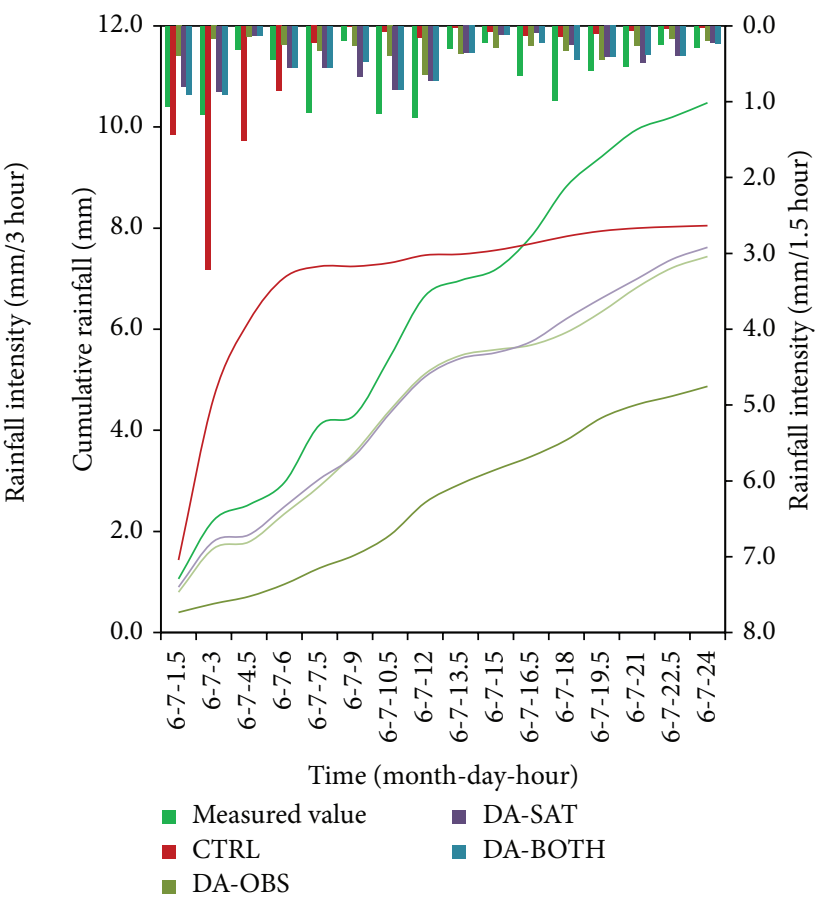

(b)

FIGURE 9: The rainfall intensities and cumulative curves of the values measured at the sites and the simulated results from the four numerical experiments: (a) Event A; (b) Event B.

0:00 to $24: 00$ on July 19 , the cumulative curves for DA-SAT and DA-SAT experiments are closer to that of the measured values compared with the other two experiments. This may be because the maximum precipitation intensities simulated by DA-BOTH and DA-SAT experiments are closer to the observed values from 6:00 to 9:00 on July 19.

In Figure 9(b) for event B, the precipitation intensity in CTRL experiment is significantly larger than the measured values in first 6 hours. Therefore, the cumulative curve in the CTRL experiment is far above that of the measured values, due to the inaccurate initial field. After data assimilation, the rainfall intensities in DA-SAT and DABOTH experiments are closer to the observations in first 6 hours, while the rainfall intensity in DA-OBS experiment is much less than the observations. As a result, the cumulative curve in DA-BOTH experiment is closest to the curve of the observed values, DA-SAT experiment is next, and DA-OBS experiment is farthest. It is noteworthy that for Event B the cumulative curve in DA-SAT experiment is closer to that of the observed values, in comparison with Event A.

The absolute error (AE) has been calculated for both Event A and Event B. In Figure 10(a) for Event A, the AE of the numerical experiments becomes bigger and bigger with the increase of rainfall intensity, while the values in DA-BOTH and DA-SAT experiments are relatively smaller. It means that, for the convective rainfall like Event A, WRF model fails in capturing the whole process of the event. However, in Figure 10(b) for Event B with even distribution in time, the $\mathrm{AE}$ of the numerical experiments is relatively constant, while the values for CTRL and DA-OBS experiments are relatively larger. 


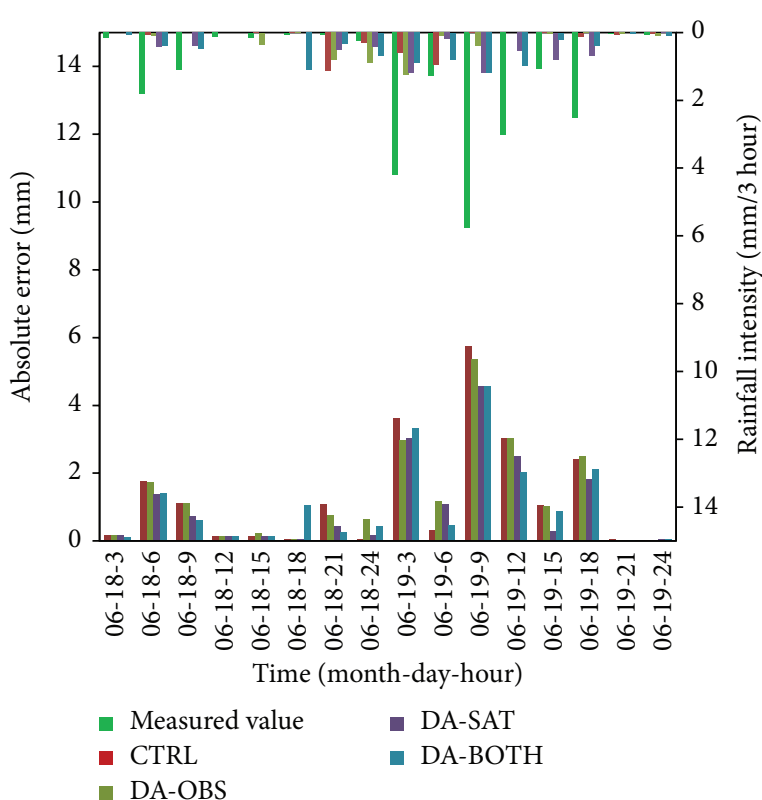

(a)

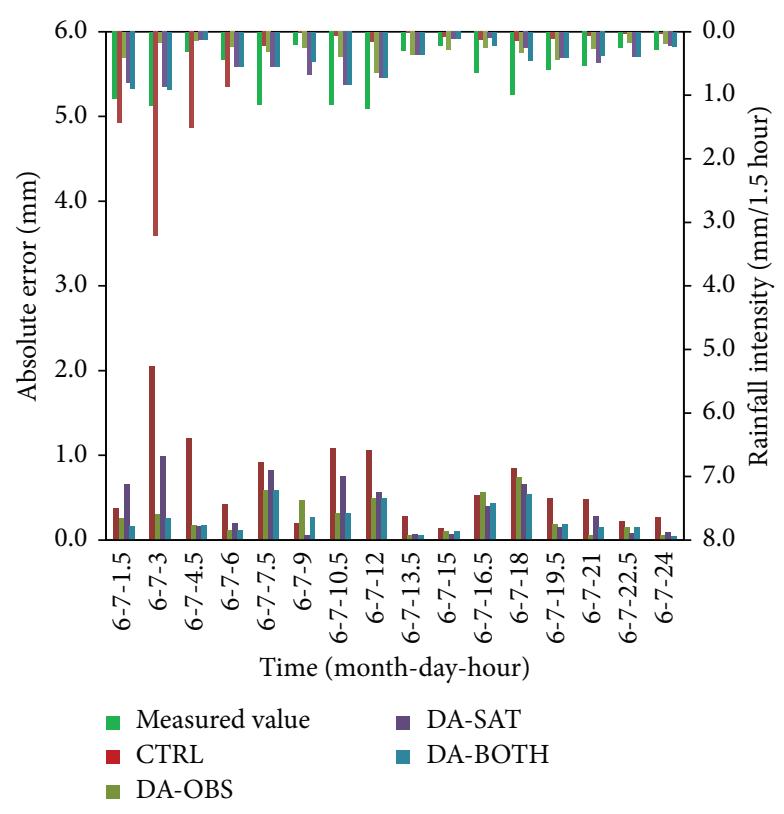

(b)

FIGURE 10: The AE of rainfall intensity between the values measured at the sites and the simulated results from the four numerical experiments: (a) Event A; (b) Event B.

The results shows that for the temporal variation of rainfall, the improvement in DA-SAT experiment is better than that in DA-OBS experiment due to the lack of ground observational data at high-altitude region. And for Event B, the improvement in DA-SAT is greater than Event A.

4.2. Impacts of Data Assimilation on the Initial Field. From the above analysis, it is clear that data assimilation experiments can improve rainfall forecast. The purpose of data assimilation is to acquire accurate initial fields for numerical models. To reveal the impact of data assimilation experiments on the initial fields, Event $A$ is chosen as an example to analyze the difference in the initial fields between data assimilation and control experiments. The geopotential height and moisture flux at $850 \mathrm{hPa}$ are selected for analysis.

Figure 11 shows the geopotential height differences between data assimilation and control experiments. Compared with CTRL experiment (Figure 11(a)), there is no evident change of geopotential height in DAOBS experiment (Figure 11(b)) or DA-SAT experiment (Figure 11(c)). Figure 8(d) shows the geopotential height for DA-BOTH experiment, which is much smaller than the values from CTRL experiment. The region with the largest changes is mainly located in Qinghai Province and the northwest of Gansu Province, which is consistent with the improved forecasts of precipitation area and accumulation in DA-BOTH experiment. As can be seen in Figure 12, after data assimilation the moisture flux change noticeably in the study area, in comparison with the control experiment (Figure 12(a)). The moisture flux of DA-SAT experiment is markedly increased in the north of the study area (Figure $12(\mathrm{~b})$ ). It may bring more precipitation in the northeast of Qinghai Province. In Figure 12(c), there is a clear flow of moisture to the northwestern part of Gansu Province which results in the heavy rain. The biggest change of moisture flux occurs in Figure 12(d) for DA-BOTH experiment, which covers the largest area compared with other numerical experiments, and it could give greatest estimated precipitation in northeastern Tibetan Plateau.

\section{Conclusions}

In this study, the 3DVar assimilation system is used to improve the forecasting of heavy rain in spatial and time distribution in northeastern Tibetan Plateau. A control and three data assimilation experiments were designed. These experiments demonstrate that the rain forecast is significantly improved after data assimilation, through enhancing the accuracy of the initial field. Two heavy rainfall events with different evenness in space and time are used to examine the improvement for rainfall forecast.

For the spatial distribution, data assimilation experiments changed significantly the rainfall area and accumulation for the study area. For Event A, the data assimilation experiments provide larger rainfall areas and accumulation, while for Event B the data assimilation experiments provide smaller precipitation accumulation on the southeastern of the study area. Rain-gauge data from 43 sites were used to evaluate the impact after data assimilation. The results shows that DA-BOTH experiment has the highest prediction accuracy, followed by the DA-SAT experiment and then DA-OBS experiment, while the CTRL experiment has the lowest accuracy. For the temporal variation, the forecast results have great differences between Event A and Event B. 


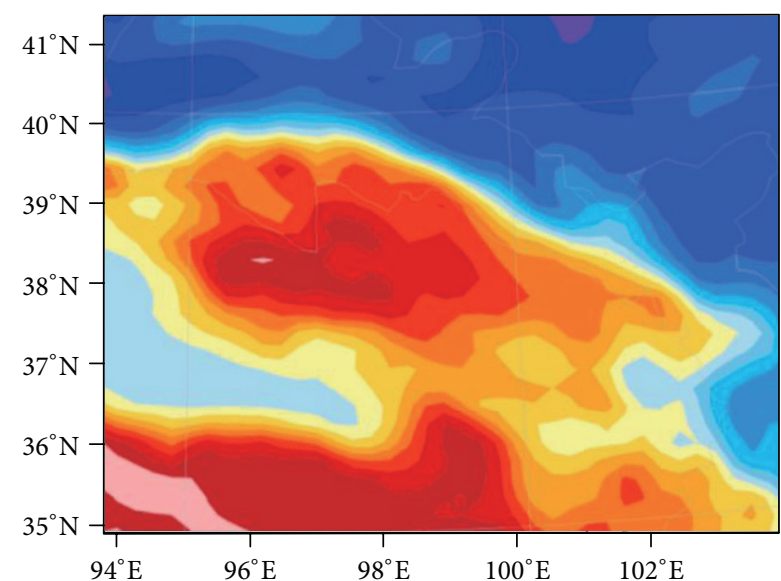

(a)

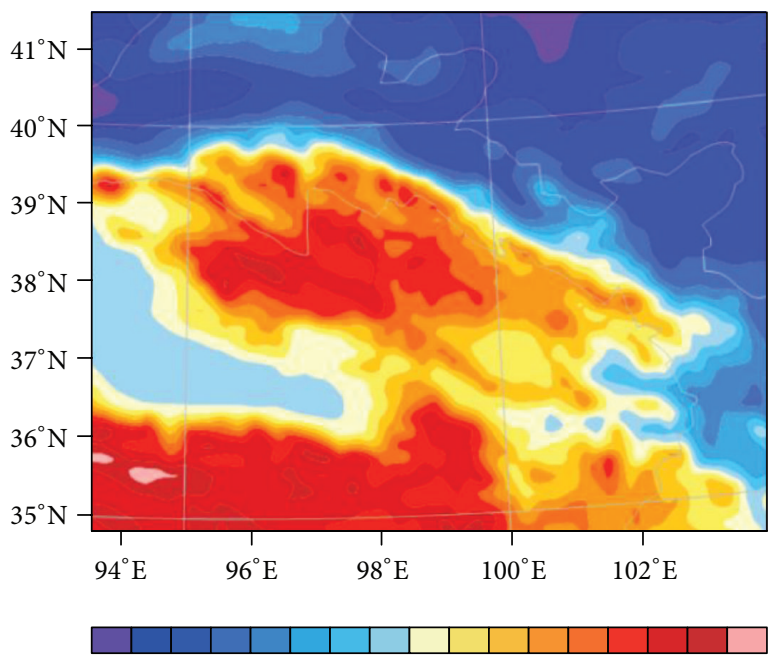

1000015000200002500030000350004000045000

$$
\left(\mathrm{m}^{2} / \mathrm{s}^{2}\right)
$$

(c)

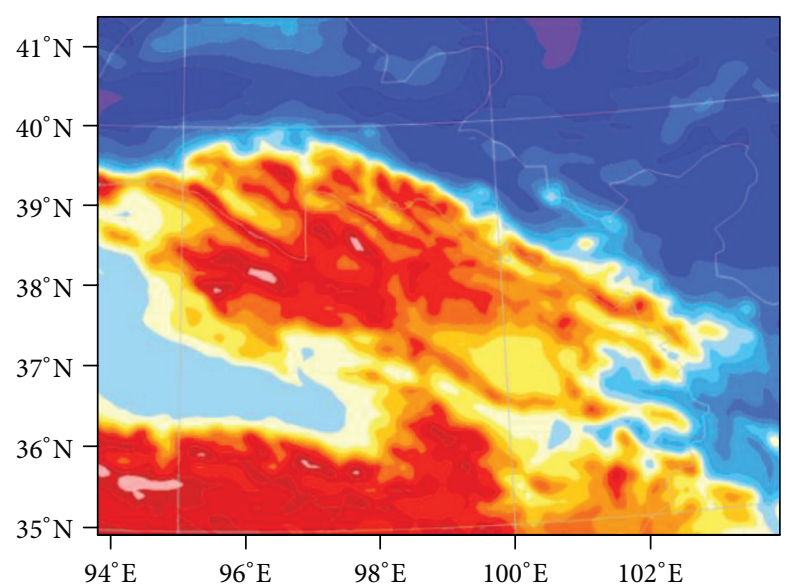

(b)

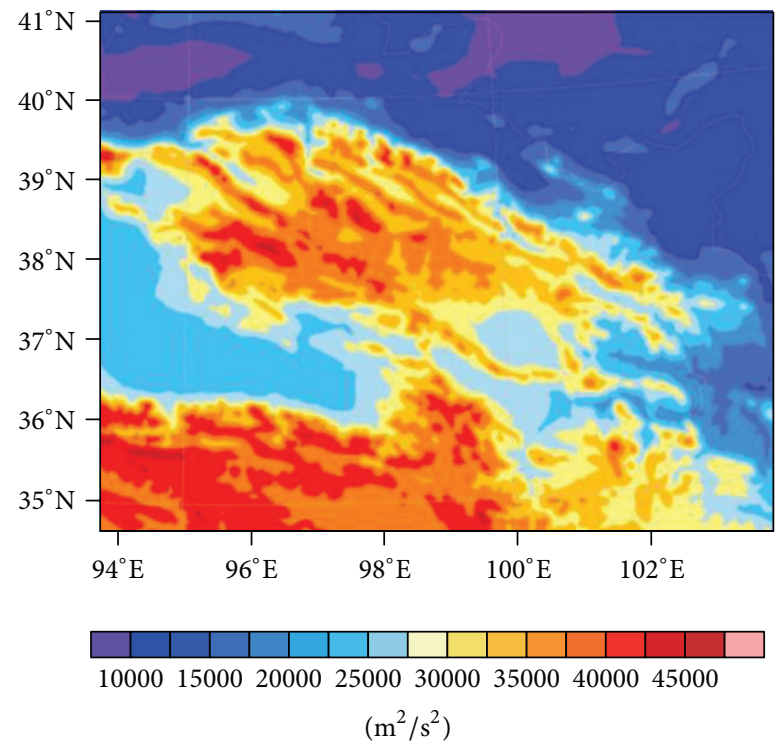

(d)

FIGURE 11: Geopotential height initial field for the CTRL and DA experiments: (a) CTRL; (b) DA-SAT; (c) DA-OBS; (d) DA-BOTH.

The satellite radiances for Event $B$ have greater positive effect than that for Event A. For the two events, the cumulative curve in DA-BOTH experiment is closest to the curve of the measured values, while in DA-OBS experiment the accumulation curves are far below to the curve of the measured values, due to the lack of ground observations in the high-altitude region. In conclusion, both for the spatial and temporal distribution of rainfall, the satellite radiances have greater effect than surface and upper-air meteorological observations in high-latitude regions of the northeastern edge, and the improvement for the assimilation of satellite radiances together with surface and upper-air meteorological observations is greater than that for assimilating either satellite radiances or meteorology observations. Event A is chosen to evaluate the impact of data assimilation on the initial fields. It is found that better and more detailed information is added to the initial fields (e.g., geopotential height and moisture flux), especially on the northwest of Gansu Province and Qinghai Province, where the forecasts of precipitation are improved significantly.

It should be mentioned that many other assimilation techniques, such as 4DVar, EnKF, and so forth, need to be tested in this study. These approaches have great potential, although they currently suffer from unaffordable computer costs. Meanwhile, we need to analyse the impact of different parameterization schemes on the WRF model after data assimilation, because in this study the conclusions drawn are subject to the specific parameterization schemes used here.

\section{Appendix}

\section{Statistic Calculation}

The coefficient of determination $\left(R^{2}\right)$, root mean square deviation (RMSE), mean error (ME), and absolute error (AE) 


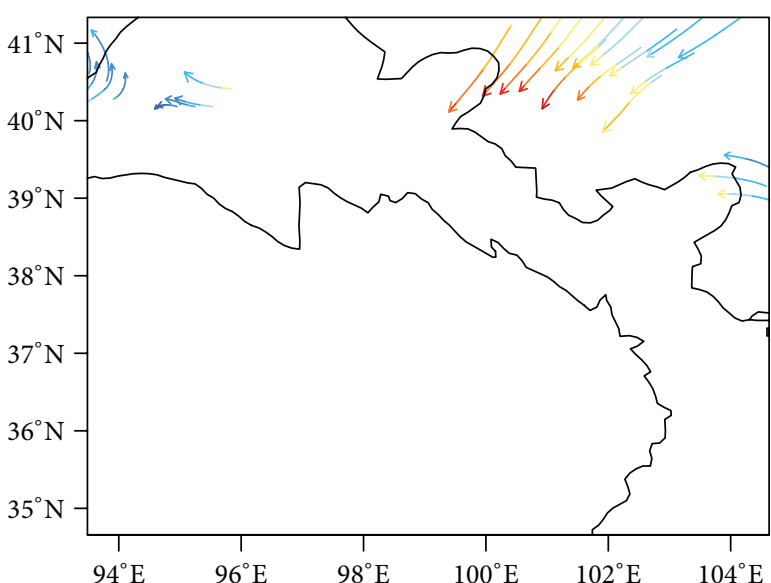

(a)

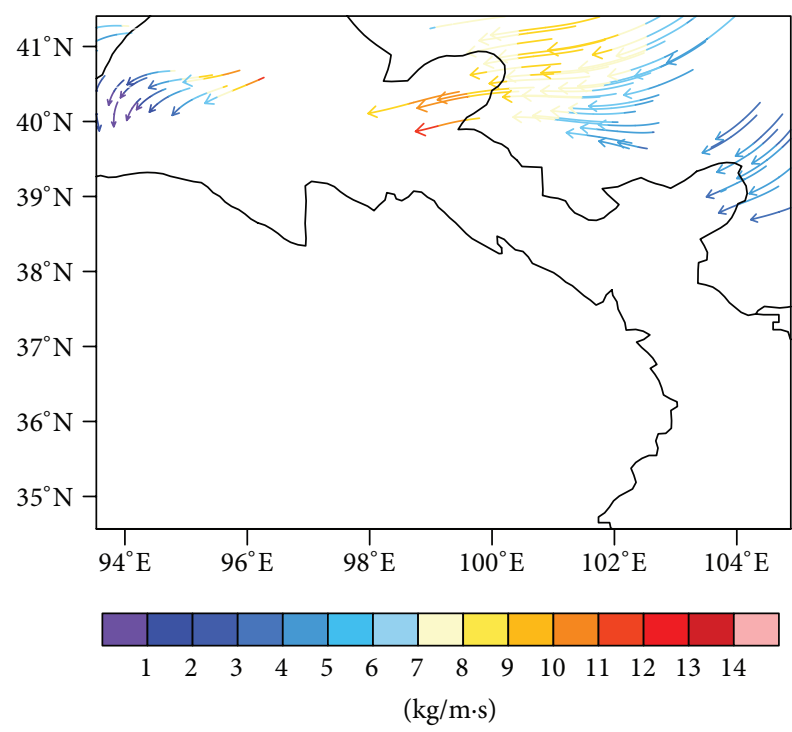

(c)

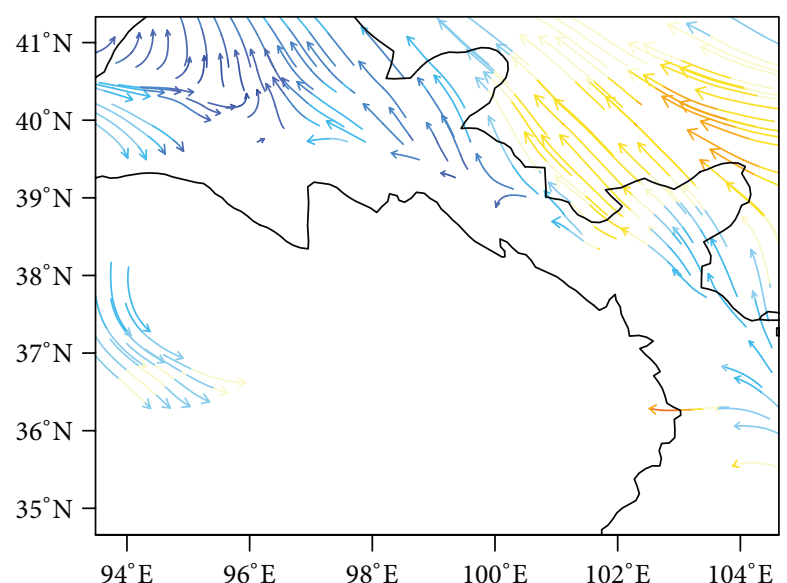

(b)

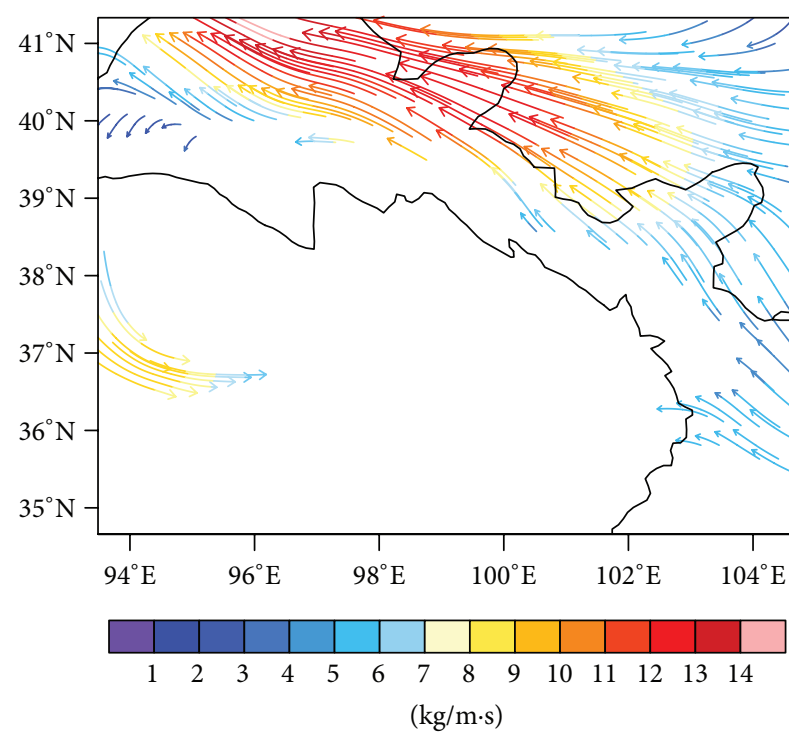

(d)

FIGURE 12: Moisture flux initial field for the CTRL and DA experiments: (a) CTRL; (b) DA-SAT; (c) DA-OBS; (d) DA-BOTH.

were used to evaluate the impact of the DA experiments in this study. They are defined as

$$
\begin{aligned}
R & \frac{(1 / N) \sum_{i=1}^{N}\left(F_{i}-\bar{F}\right)\left(O_{i}-\bar{O}\right)}{\sqrt{(1 / N) \sum_{i=1}^{N}\left(F_{i}-\bar{F}\right)^{2}} \sqrt{(1 / N) \sum_{i=1}^{N}\left(O_{i}-\bar{O}\right)^{2}}}, \\
\operatorname{RMSE} & =\sqrt{\frac{1}{N} \sum_{i=1}^{N}\left(F_{i}-O_{i}\right)^{2},} \\
\mathrm{ME} & =\frac{1}{N} \sum_{i=1}^{N}\left(O_{i}-F_{i}\right), \\
\mathrm{AE} & =\frac{1}{N} \sum_{i=1}^{N}\left|F_{i}-O_{i}\right| .
\end{aligned}
$$

Here, $F$ is simulated value; $O$ is observed value; $N$ is the number of sites.

\section{Conflict of Interests}

The authors declare that there is no conflict of interests regarding the publication of this paper.

\section{Acknowledgments}

This work was supported by the National natural Science Foundation of China (41190080, 40971290), Strategic Leading Technology Special Fund of Chinese Academy of Sciences (XDB03030204), the National Scientific and Technological Support Project (2013BAB05B03), and the Opening Fund of Key Laboratory of Land Surface Process and Climate Change in Cold and Arid Regions, CAS (LPCC201205). 


\section{References}

[1] P. Chambon, S. Q. Zhang, A. Y. Hou, M. Zupanski, and S. Cheung, "Assessing the impact of pre-GPM microwave precipitation observations in the Goddard WRF ensemble data assimilation system," Quarterly Journal of the Royal Meteorological Society, vol. 140, no. 681, pp. 1219-1235, 2013.

[2] J.-H. Seo, Y. H. Lee, and Y.-H. Kim, "Feature selection for very short-term heavy rainfall prediction using evolutionary computation," Advances in Meteorology, vol. 2014, Article ID 203545, 15 pages, 2014.

[3] D. Argüeso, J. M. Hidalgo-Muñoz, S. R. Gámiz-Fortis, M. J. Esteban-Parra, and Y. Castro-Díez, "High-resolution projections of mean and extreme precipitation over Spain using the WRF model (2070-2099 versus 1970-1999)," Journal of Geophysical Research D: Atmospheres, vol. 117, no. 12, Article ID D12108, 2012.

[4] D. Argüeso, J. M. Hidalgo-Muñoz, S. R. Gámiz-Fortis, M. J. S. Esteban-Parra, and Y. Castro-Díez, "Evaluation of WRF mean and extreme precipitation over Spain: present climate (197099)," Journal of Climate, vol. 25, no. 14, pp. 4883-4895, 2012.

[5] R. M. Cardoso, P. M. M. Soares, P. M. A. Miranda, and M. Belo-Pereira, "WRF high resolution simulation of Iberian mean and extreme precipitation climate," International Journal of Climatology, vol. 33, no. 11, pp. 2591-2608, 2013.

[6] L. Calvetti and A. J. Pereira Filho, "Ensemble hydrometeorological forecasts using WRF hourly QPF and topmodel for a middle watershed," Advances in Meteorology, vol. 2014, Article ID 484120, 12 pages, 2014.

[7] S. Q. Zhang, M. Zupanski, A. Y. Hou, X. Lin, and S. H. Cheung, "Assimilation of precipitation-affected radiances in a cloudresolving wrf ensemble data assimilation system," Monthly Weather Review, vol. 141, no. 2, pp. 754-772, 2013.

[8] J. Liu, M. Bray, and D. Han, "Exploring the effect of data assimilation by WRF-3DVar for numerical rainfall prediction with different types of storm events," Hydrological Processes, vol. 27, no. 25, pp. 3627-3640, 2013.

[9] C.-H. Xiong, L.-F. Zhang, J.-P. Guan, J. Peng, and B. Zhang, "Analysis and numerical study of a hybrid BGM-3DVAR data assimilation scheme using satellite radiance data for heavy rain forecasts," Journal of Hydrodynamics, vol. 25, no. 3, pp. 430-439, 2013.

[10] D. M. Barker, W. Huang, Y. R. Guo, and Q. N. Xiao, "A threedimensional (3DVAR) data assimilation system for use with MM5: implementation and initial results," Monthly Weather Review, vol. 132, pp. 897-914, 2004.

[11] Q. Xiao and J. Sun, "Multiple-radar data assimilation and shortrange quantitative precipitation forecasting of a squall line observed during IHOP 2002," Monthly Weather Review, vol. 135, no. 10, pp. 3381-3404, 2007.

[12] Z. Sokol, "Effects of an assimilation of radar and satellite data on a very-short range forecast of heavy convective rainfalls," Atmospheric Research, vol. 93, no. 1-3, pp. 188-206, 2009.

[13] P. Bauer, P. Lopez, A. Benedetti, D. Salmond, and E. Moreau, "Implementation of 1D+4D-Var assimilation of precipitationaffected microwave radiances at ECMWF. I: 1D-Var," Quarterly Journal of the Royal Meteorological Society, vol. 132, no. 620, pp. 2277-2306, 2006.

[14] P. Bauer, P. Lopez, D. Salmond, A. Benedetti, S. Saarinen, and M. Bonazzola, "Implementation of $1 \mathrm{D}+4 \mathrm{D}$-Var assimilation of precipitation-affected microwave radiances at ECMWF. II: 4DVar," Quarterly Journal of the Royal Meteorological Society, vol. 132, no. 620, pp. 2307-2332, 2006.

[15] P. Bauer, A. J. Geer, P. Lopez, and D. Salmond, "Direct 4DVar assimilation of all-sky radiances. Part I. Implementation," Quarterly Journal of the Royal Meteorological Society, vol. 136, no. 652, pp. 1868-1885, 2010.

[16] A. J. Geer, P. Bauer, and P. Lopez, "Direct 4D-Var assimilation of all-sky radiances. Part II: assessment," Quarterly Journal of the Royal Meteorological Society, vol. 136, no. 652, pp. 1886-1905, 2010.

[17] Z. Sokol and D. Rezacova, "Assimilation of radar reflectivity into the LM COSMO model with a high horizontal resolution," Meteorological Applications, vol. 13, no. 4, pp. 317-330, 2006.

[18] Z. Sokol, "Assimilation of extrapolated radar reflectivity into a NWP model and its impact on a precipitation forecast at high resolution," Atmospheric Research, vol. 100, no. 2-3, pp. 201-212, 2011.

[19] H. Wang, J. Sun, S. Fan, and X.-Y. Huang, "Indirect assimilation of radar reflectivity with WRF 3D-var and its impact on prediction of four summertime convective events," Journal of Applied Meteorology and Climatology, vol. 52, no. 4, pp. 889902, 2013.

[20] B. Macpherson, "Operational experience with assimilation of rainfall data in the Met Office mesoscale model," Meteorology and Atmospheric Physics, vol. 76, no. 1-2, pp. 3-8, 2001.

[21] K. Stephan, S. Klink, and C. Schraff, "Assimilation of radarderived rain rates into the convective-scale model COSMO-DE at DWD," Quarterly Journal of the Royal Meteorological Society, vol. 134, no. 634, pp. 1315-1326, 2008.

[22] K. Alapaty, D. S. Niyogi, F. Chen, P. Pyle, A. Chandrasekar, and N. Seaman, "Development of the flux-adjusting surface data assimilation system for mesoscale models," Journal of Applied Meteorology and Climatology, vol. 47, no. 9, pp. 2331-2350, 2008.

[23] F. H. Ruggiero, G. D. Modica, and A. E. Lipton, "Assimilation of satellite imager data and surface observations to improve analysis of circulations forced by cloud shading contrasts," Monthly Weather Review, vol. 128, no. 2, pp. 434-448, 2000.

[24] J. P. Hacker and D. Rostkier-Edelstein, "PBL state estimation with surface observations, a column model, and an ensemble filter," Monthly Weather Review, vol. 135, no. 8, pp. 2958-2972, 2007.

[25] D. J. Stensrud, N. Yussouf, D. C. Dowell, and M. C. Coniglio, "Assimilating surface data into a mesoscale model ensemble: cold pool analyses from spring 2007," Atmospheric Research, vol. 93, no. 1-3, pp. 207-220, 2009.

[26] Q. Wan and J. Xu, "A numerical study of the rainstorm characteristics of the June 2005 flash flood with WRF/GSI data assimilation system over south-east China," Hydrological Processes, vol. 25, no. 8, pp. 1327-1341, 2011.

[27] J. Liu, M. Bray, and D. Han, "A study on WRF radar data assimilation for hydrological rainfall prediction," Hydrology and Earth System Sciences, vol. 17, no. 8, pp. 3095-3110, 2013.

[28] K. Ide, P. Courtier, M. Ghil, and A. C. Lorenc, "Unified notation for data assimilation: operational, sequential and variational," Journal of the Meteorological Society of Japan, vol. 75, no. 1, pp. $181-189,1997$.

[29] A. C. Lorenc, "Analysis methods for numerical weather prediction," Quarterly Journal of the Royal Meteorological Society, vol. 112 , no. 474, pp. 1177-1194, 1966. 
[30] D. F. Parrish and J. C. Derber, "The national meteorological center's spectral statistical interpolation analysis system," Monthly Weather Review, vol. 120, no. 8, pp. 1747-1763, 1992.

[31] T. B. Zhao and C. B. Fu, "Preliminary comparison and analysis between ERA-40, NCEP-2 reanalysis and observations over China," Climatic and Environmental Research, vol. 11, no. 1, pp. 14-32, 2006.

[32] L. Ma, T. Zhang, Q. Li, O. W. Frauenfeld, and D. Qin, "Evaluation of ERA-40, NCEP-1, and NCEP-2 reanalysis air temperatures with ground-based measurements in China," Journal of Geophysical Research: Atmospheres (1984-2012), vol. 13, no. D15, 1984. 

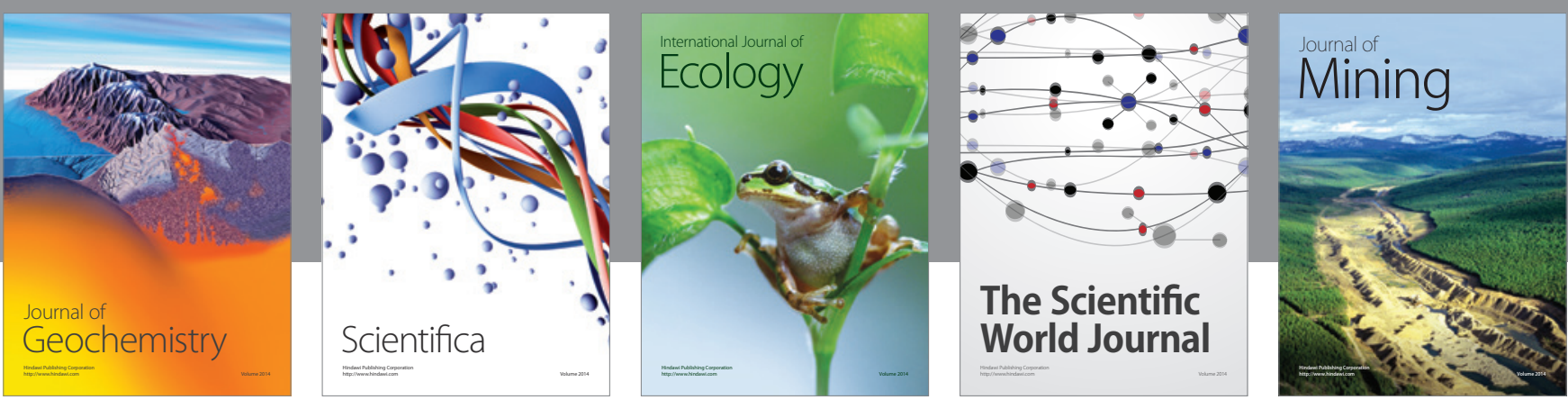

The Scientific World Journal
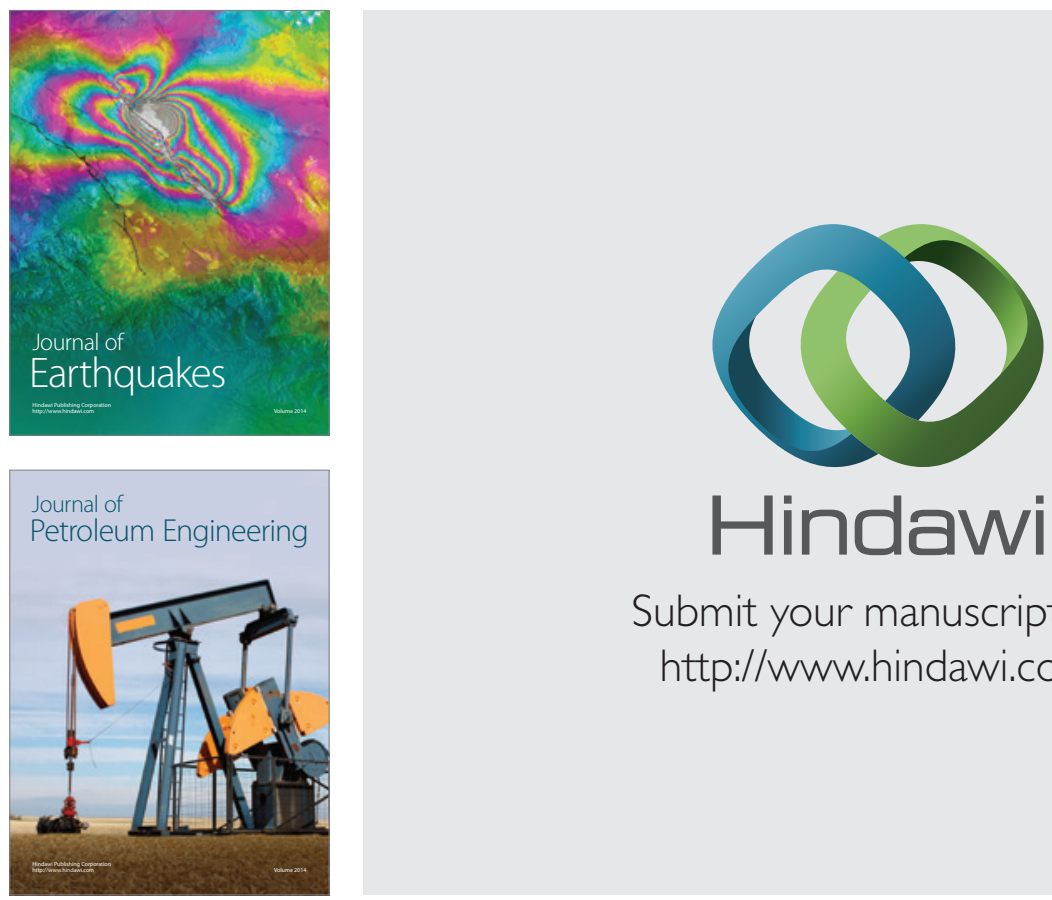

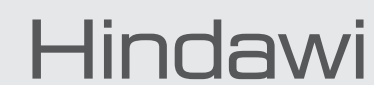

Submit your manuscripts at

http://www.hindawi.com
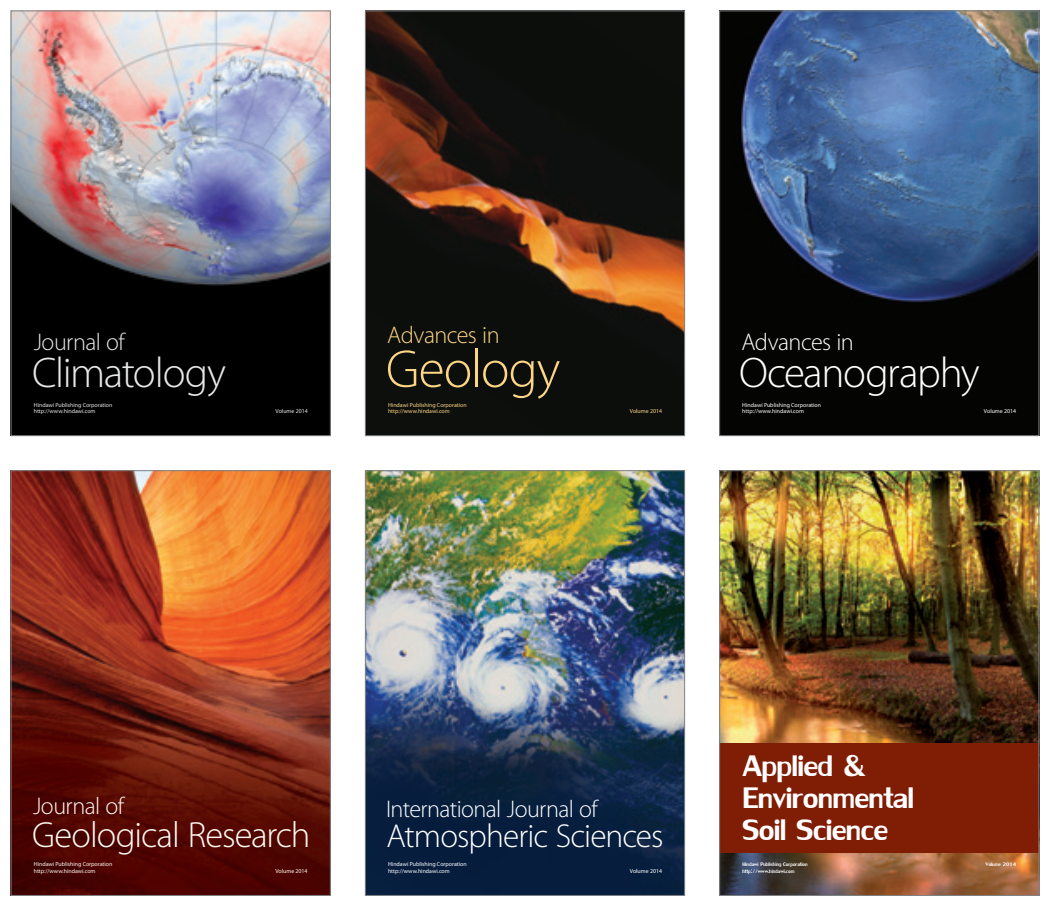
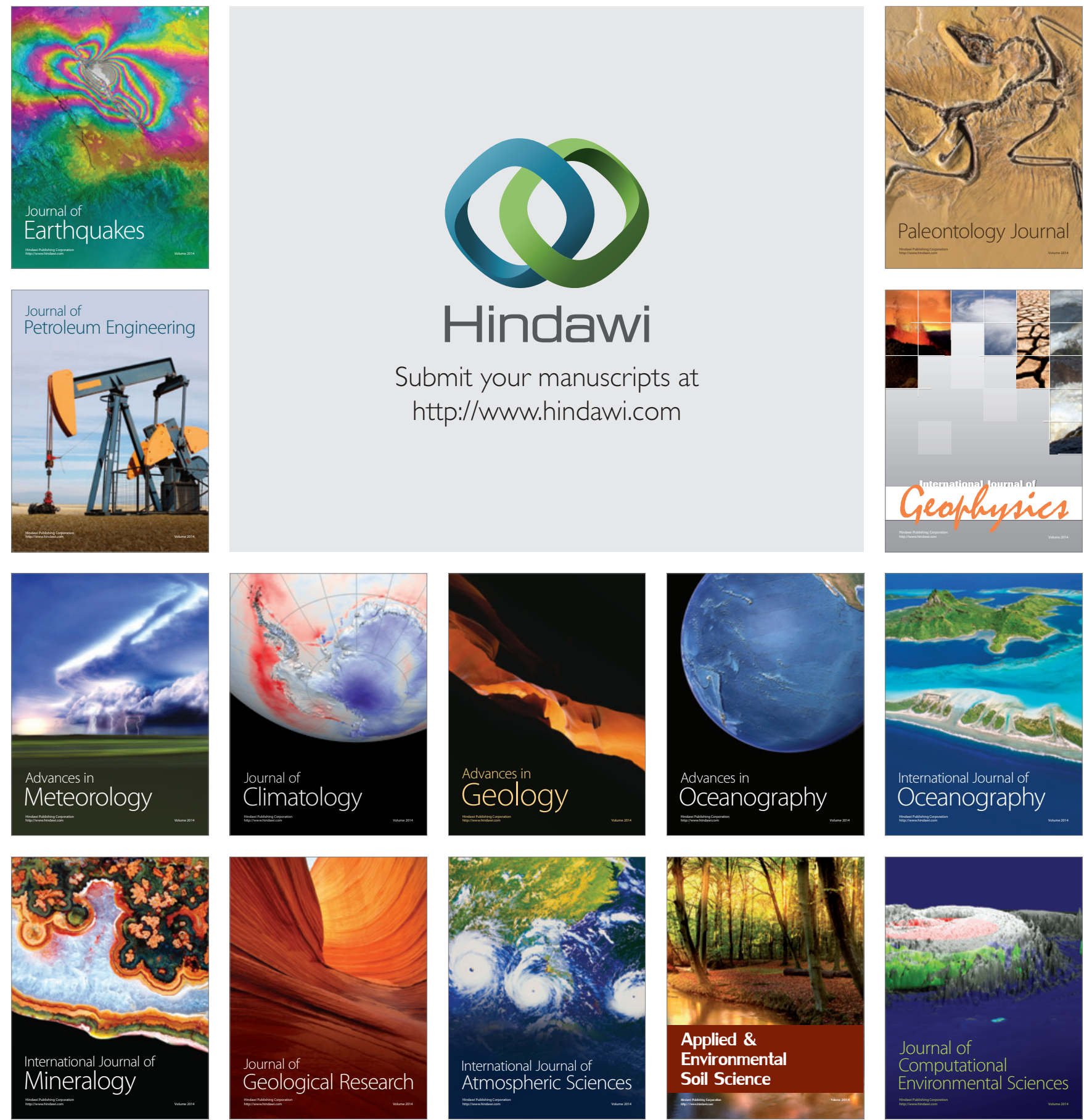